\title{
Antitumor effects and mechanisms of total saponin and total flavonoid extracts from Patrinia villosa (Thunb.) Juss
}

\author{
Li-xia GUO and Xue GAO*
}

Research Centre of Medicinal Chemistry and Chemical Biology, Chongqing Technology and Business University, Chongqing 400067, China.

Accepted 19 November, 2012

\begin{abstract}
Patrinia villosa (Thunb.) Juss is a Chinese edible herbal widely used in China for treatment of carbuncles, acute appendicitis, hepatitis and stasis for hundreds of years. In this study, the antitumor effects and the possible mechanisms of total saponin extract from $P$. villosa (SPV) and total flavonoid extract from $P$. villosa (FPV) were investigated in four cancer cell lines including mouse melanoma cell line B16, MCF-7 human breast cancer cells, Hela human epithelial cervical cancer cells and L1210 mouse lymphocytic leukemia cells. The antiproliferative effects of SPV and FPV on these cells were observed by 3-(4,5-Dimethyithiazol-2-yl)-2,5-diphenyl-tetrazolium bromide (MTT) assay. The cell cycle was detected by flow cytometry. The expression of CDK4 and cyclin D1 were measured by western blot. The results of MTT assay suggested that FPV showed much stronger antiproliferative effects on L1210 cells in a dose-dependent manner. On the other hand, SPV showed better antiproliferative effect than FPV on the other three cell lines in a dose-dependent manner. The mechanism of antitumor effect of SPV and FPV might be the inhibition of expression of CDK4 and cyclin D1, and accordingly arrested four cancer cell lines in G0/G1 phase, decreased the number of cells in S phase, and finally induced antiproliferative effect. In summary, pharmacological data obtained from this study suggested that SPV and FPV possessed cancer chemopreventive potential on different types of cancer cells. These results were much more favorable on bioactivity-guided isolations of SPV and FPV.
\end{abstract}

Key words: Patrinia villosa (Thunb.) Juss, saponins, flavonoids, antitumor, mechanism.

\section{INTRODUCTION}

Patrinia villosa (Thunb.) Juss (Valerianaceae), an herbaceous plant, is distributed mainly in East Asia and Northeast North America. It is a commonly used herbal medicine in China for treatment of carbuncles, acute appendicitis, hepatitis, amygdalitis, angina parotidea, anthracia, stasis, intestinal abscess, postpartum pain, dysmenorrhoea and endometriosis for hundreds of years. Little biological activity of $P$. villosa constituents was evaluated, although $P$. villosa was reported to be a rich source of flavonoids (Peng et al., 2006a, 2005a, 2006c, d, 2005c). The proangiogenic activity of the extract of $P$.

*Corresponding author. E-mail: gaoxue@ctbu.edu.cn. Tel/Fax: 86-23-6276-9652. villosa is confirmed by an in vitro mouse aortic ring assay and an in vivo murine hindlimb ischemia model (Jeon et al., 2010). Yang et al. (2006) showed that the whole extracts of $P$. villosa extract improved myocardial and cerebral oxygen consumption. Moreover, saponin extract from $P$. villosa effectively reduced the weight of U14 cervical tumor, inhibited proliferating cell nuclear antigen (PCNA) of tumor cell, decreased the expression of mutant p53 and bcl-2 protein (Zhang et al., 2008). However, little is known about a systematic comparison of antitumor effects on different cell lines between the total saponin extract from P. villosa (SPV) and the total flavonoid extract from $P$. villosa (FPV) and the signaling mechanisms responsible for their biological activity. Therefore, in this study, the antitumor effects and the possible mechanisms of SPV and FPV were investigated 
in four cancer cell lines including mouse melanoma cell line B16, MCF-7 human breast cancer cells, Hela human epithelial cervical cancer cells and L1210 mouse lymphocytic leukemia cells.

\section{MATERIALS AND METHODS}

\section{Chemicals and reagents}

Cell culture media, phosphate buffer solution (PBS) and fetal bovine serum (FBS) were from Gibco (Tulsa, OK, USA). All cell culture plastic ware (COSTAR®) was purchased from Corning (New York, USA). 3-(4,5-Dimethyithiazol-2-yl)-2,5-diphenyltetrazolium bromide (MTT) was from Promega Corporation (WI, USA). The Via Count Assay kit, the Guava Cell Cycle kit and enhanced chemiluminescence detection kit were from Millipore (Millipore Corporation, Hayward, CA). Antibodies for CDK4 (sc200), cyclin D1 (sc-575) and secondary antibodies were obtained from Santa Cruz Biotechnology Inc. (CA, USA). Macroporous resin D101 was purchased from the Chemical Plant of NanKai University (Tianjin, China).

\section{Plant}

The whole plants of $P$. villosa were collected in September, 2009 at Changbai Mountains, Tonghua, People's Republic of China, and identified by Associate Professor Hong Zhao, Marine College, Shandong University at Weihai. A voucher specimen (No. CB 2009007) was deposited in the Herbarium of Laboratory of Botany, Research Center of Medical Chemistry and Chemical Biology, Chongqing Technology and Business University.

\section{Extraction}

\section{Extraction of SPV}

Dried $P$. villosa rhizomes were pulverized and extracted with $95 \%$ ethanol. The solvent of the extract solution was evaporated under vacuum. The dried extract was dissolved in water, and then extracted with petroleum ether. The water phase was absorbed by macroreticular resin D101. The SPV was eluted with $75 \%$ ethanol aqueous solution, followed by lyophilizing to give the extract (Xu et al., 2006).

\section{Extraction of FPV}

Dried $P$. villosa rhizomes were pulverized and extracted with $75 \%$ ethanol by Suoshi extraction method and the flavonoids content was measured using ultraviolet (UV) spectrum (Xu et al., 2004).

\section{Cell lines}

The mouse melanoma cell line B16, MCF-7 human breast cancer cells and Hela human epithelial cervical cancer cells were cultured in Dulbecco's Modified Eagle's Medium (DMEM) supplemented with $2 \mathrm{mM}$ L-glutamine and $10 \%$ foetal calf serum. L1210 mouse lymphocytic leukemia cells were cultured in RPMI 1640 media supplemented with $2 \mathrm{mM}$ L-glutamine and $10 \%$ foetal calf serum. All cells were cultured in media supplemented with $1 \%$ penicillin/streptomycin and kept at $37^{\circ} \mathrm{C}$ and humidified in $5 \% \mathrm{CO}_{2}$.

\section{Growth inhibition analysis}

SPV and FPV were dissolved in dimethyl sulfoxide (DMSO). Cells were seeded in 6-well plates. After 1 day, various concentrations of extracts were added to the wells. The final concentration of DMSO was $0.5 \%$. Controls were exposed to culture medium containing $0.5 \%$ DMSO without drugs. Cell proliferation was evaluated using an MTT assay. The dark blue formazan crystals formed in intact cells were solubilized with DMSO, and optical densities at $570 \mathrm{~nm}$ was measured with a TECAN infinite M200 (TECAN Group Ltd).

\section{Cell proliferation analysis}

Cells were routinely seeded into 6 -well plates at $2 \times 10^{4}$ cells/well and incubated at $37^{\circ} \mathrm{C}$ for $24 \mathrm{~h}$. Cells were incubated with various concentrations of extracts for $48 \mathrm{~h}$. At the end of this time, the cells were trypsinized to produce a single cell suspension, and the viable cell number in each well was counted using the Via Count Assay (Guava Technologies, Hayward, CA).

\section{Cell cycle analysis}

Cells were trypsinized, centrifuged, and fixed in ice-cold $70 \%$ ethanol at $4^{\circ} \mathrm{C}$ for 16 to $24 \mathrm{~h}$. Evaluation of cell cycle was carried out using the Guava Cell Cycle Kit. Cell pellets were resuspended in $200 \mu \mathrm{l}$ Guava Cell Cycle Reagent for $30 \mathrm{~min}$ at room temperature, shielded from light. The stained cells were analyzed

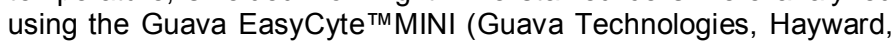
$\mathrm{CA}$ ) and data were analyzed using the Guava CytoSoft software package.

\section{Western blot analysis}

For Western blot analysis, $30 \mu \mathrm{g}$ samples of cell extract were resolved by sodium dodecyl sulfate-polyacrylamide gel electrophoresis (SDS-PAGE) and immunoblotted. The following primary antibodies were used: rabbit polyclonal antibodies to CDK4 (sc200), cyclin D1 (sc-575) at 1:5000 dilutions for $2 \mathrm{~h}$. The antigenantibody complex was then detected by incubating the membrane for another $1 \mathrm{~h}$ in buffer containing a 1:5000 dilution of horseradish peroxidase-conjugated anti-rabbit immunoglobin $\mathrm{G}(\mathrm{IgG})$ secondary antibody. Excess antibody was washed off with $20 \mathrm{mM}$ TBST (20 $\mathrm{mM}$ Tris, $150 \mathrm{mM} \mathrm{NaCl}, \mathrm{pH} \mathrm{7.5}$, and $0.1 \%$ Tween 20). Detection was performed using enhanced chemiluminescence detection kit. Band intensities were quantified with the software of quantity one.

\section{Statistical analysis}

Results are given as means \pm standard deviation (SD). Student's two-tailed $t$-test or one-way analysis of variance was used to determine significant differences between two means $(P<0.05$ or $\mathrm{P}<0.01)$.

\section{RESULTS}

\section{Antiproliferative effects of SPV and FPV on different cancer cell lines}

The cell growth inhibitory effects of SPV and FPV on four cancer cell lines were determined using the MTT assay. As shown in Figure 1A, compared with SPV, FPV showed much stronger antiproliferative effects on L1210 
A

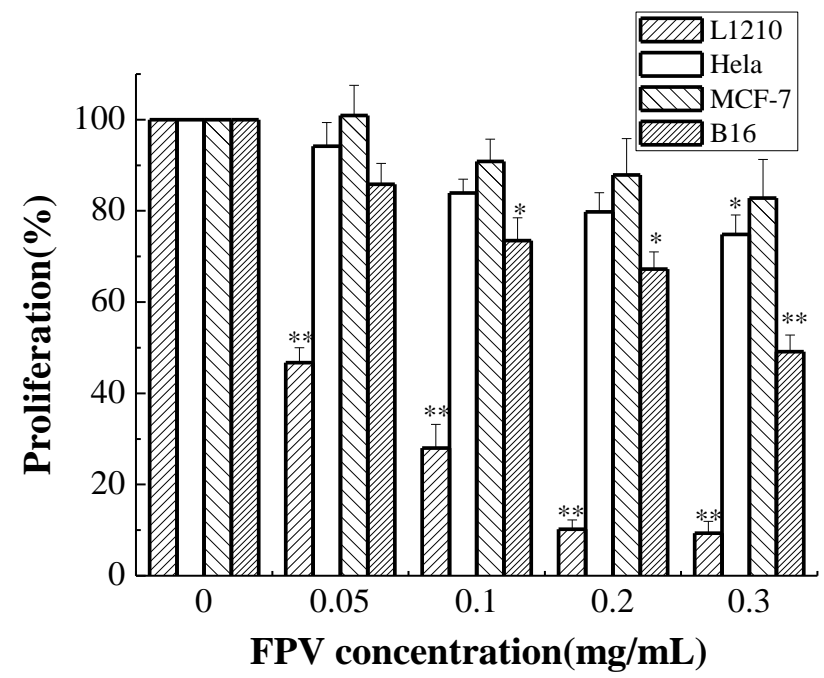

B

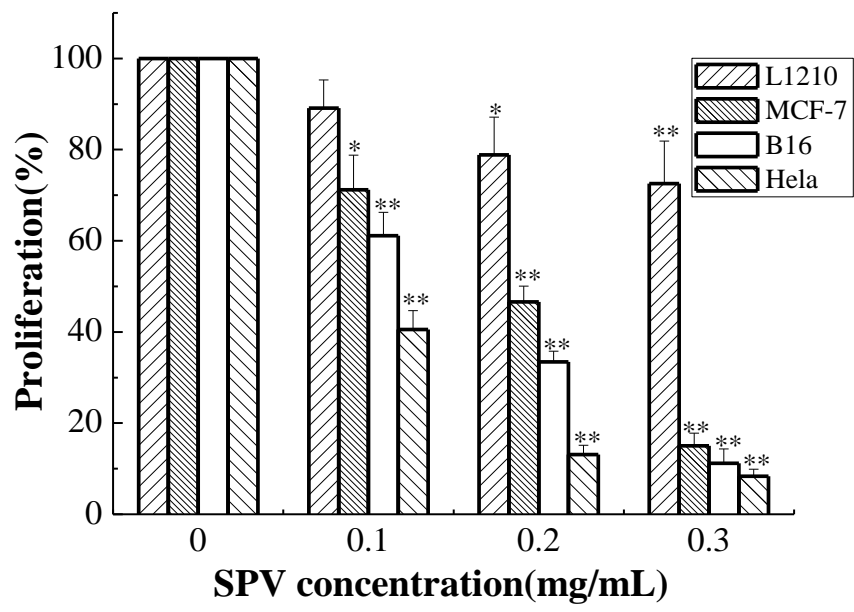

Figure 1. Effects of SPV (A) and FPV (B) on proliferation of different cancer cell lines assayed by MTT method. Cells were treated with indicated concentration extracts for $48 \mathrm{~h}$. L1210 cells are more sensitive to FPV, while Hela, MCF-7 and B16 cells are more sensitive to SPV. ${ }^{*} \mathrm{P}<0.05$ and ${ }^{* *} \mathrm{P}<0.01$ versus control.

cells in a dose-dependent manner $(\mathrm{P}<0.01)$. On the other hand, SPV showed better antiproliferative effects than FPV on the other three cell lines in a dose-dependent manner $(P<0.01)$, including Hela, MCF-7 and B16 cells (Figure 1B). The most potent antiproliferative effects were observed on Hela cells treated with SPV and L1210 cell lines treated with FPV. At $0.1 \mathrm{mg} / \mathrm{ml}$ for $48 \mathrm{~h}$, the FPV inhibited cell growth by $72.1 \%$ in the L1210 cell line, and SPV by $59.5 \%$ in the Hela cells, respectively. The results of flow cytometry analysis showed the same trend as with MTT assay. As shown in Figure 2, the percentage of dead cells increased significantly after $48 \mathrm{~h}$ of treatment, and the inhibition rates of the cell proliferation were similar with MTT assay results for both extracts.

\section{Effects of SPV and FPV on cell cycle}

To explore the potential mechanism of SPV and FPV inhibited cell growth, the cell cycle profile was assayed by flow cytometry after staining with propidium iodide (PI). Based on the MTT and ViaCount assay data, the effect of SPV on Hela, MCF-7, and B16 cells cycle and of FPV on L1210 cells cycle were evaluated.

As shown in Table 1, the S-phase population of four different cell lines significantly decreased in dosedependent manners $(P<0.01)$. Compared with the control, cell cycle profile was changed after $48 \mathrm{~h}$ treatment. FPV treatment obviously decreased S-phase cells of L1210 cells at 0.02 and $0.05 \mathrm{mg} / \mathrm{ml}$. However, the 0.05 and 0.1 $\mathrm{mg} / \mathrm{ml}$ of SPV decreased S-phase cells of other three cell lines.

\section{Effects of SPV and FPV on expression of CDK4 and cyclin D1}

It was reported that cyclin D1 and its catalytic partner CDK4 played important roles in the G1/S checkpoint of the cell cycle. To observe additional information involved in the cell cycle regulations, the expression of cyclin D1 in Hela, MCF-7, B16 and L1210 cancer cells was evaluated (Figure 3). FPV down-regulated the expressions of cyclin D1 and CDK4 in a dose-dependent manner in L1210 cells. In the same way, SPV down-regulated the expressions of the two proteins in a dose-dependent manner in Hela, MCF-7 and B16 cells. As shown in Figure 3B compared to the control, the incubation in Hela cells with 0.05 and $0.1 \mathrm{mg} / \mathrm{ml} \mathrm{SPV} \mathrm{for} 48 \mathrm{~h}$, resulted in decreased of CDK4 to 39.6 and $19.5 \%$ and cyclin D1 also decreased to 13.2 and $8.1 \%$, respectively. In L1210 cells, incubation with 0.03 and $0.05 \mathrm{mg} / \mathrm{ml} \mathrm{FPV} \mathrm{for} 48 \mathrm{~h}$, resulted in decreased of CDK4 to 59.7 and $22.0 \%$ and cyclin D1 also decreased to 49.0 and $21.1 \%$, respectively.

\section{DISCUSSION}

$P$. villosa is used to treat bowel cancer and carcinoma of the bladder. However, there are no report about a systematic comparison of antitumor effects on different cell lines between SPV and FPV, although many of the components have been separated (Peng et al., 2006a, b, 2005a, b) and antitumor effects of SPV on mice bearing U14 cervical cancer had been researched (Zhang et al., 2008).

In this study, we compared the antiproliferative potential of SPV and FPV using four cancer cell lines. The cancer cell lines used includes four types of cancers, mouse melanoma cell line B16, MCF-7 human breast cancer cells, Hela human epithelial cervical cancer cells and L1210 mouse lymphocytic leukemia cells. The results of MTT assay showed that the FPV inhibited the 
FPV $0(\mathrm{mg} / \mathrm{ml})$

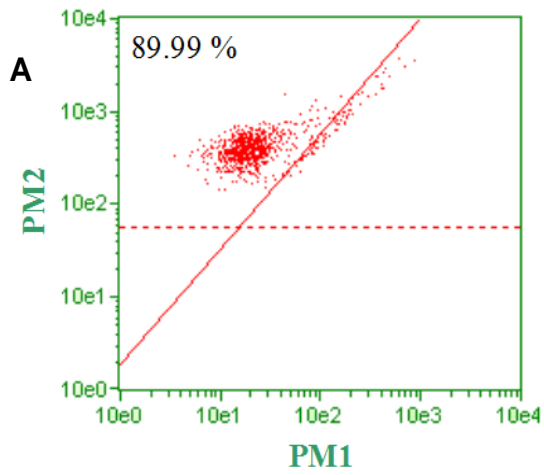

SPV $0(\mathrm{mg} / \mathrm{ml})$

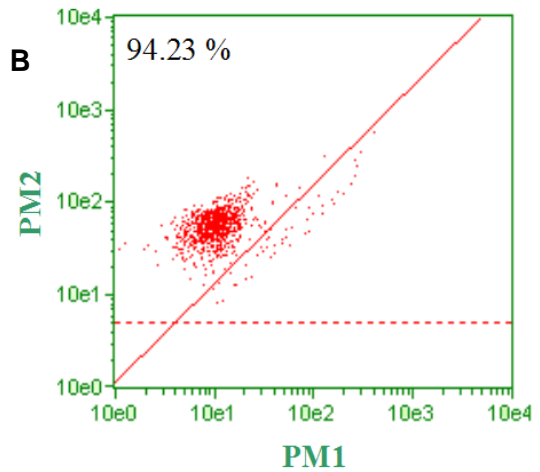

SPV $0(\mathrm{mg} / \mathrm{ml})$

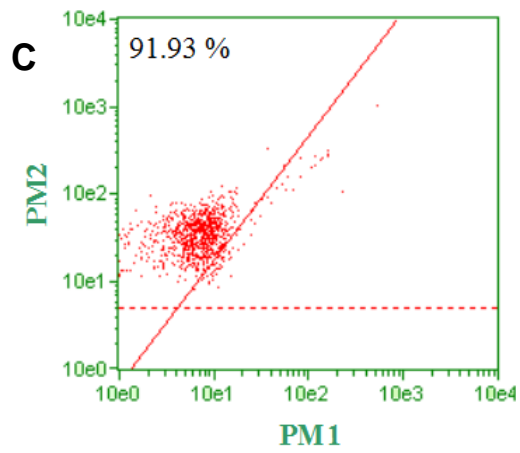

SPV $0(\mathrm{mg} / \mathrm{ml})$

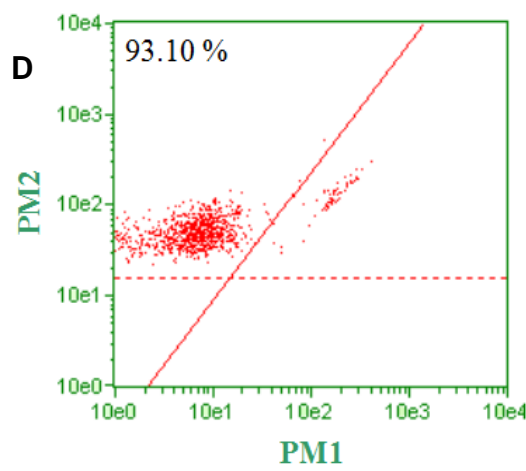

FPV $0.05(\mathrm{mg} / \mathrm{ml})$

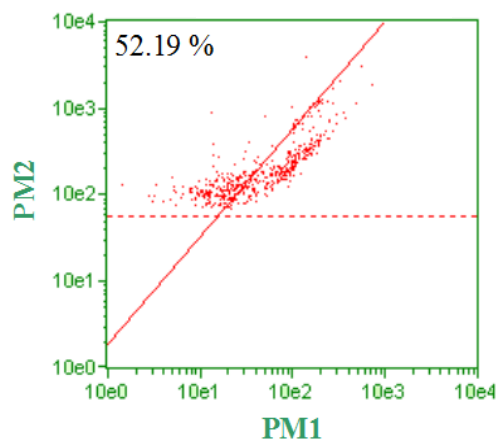

SPV $0.05(\mathrm{mg} / \mathrm{ml})$

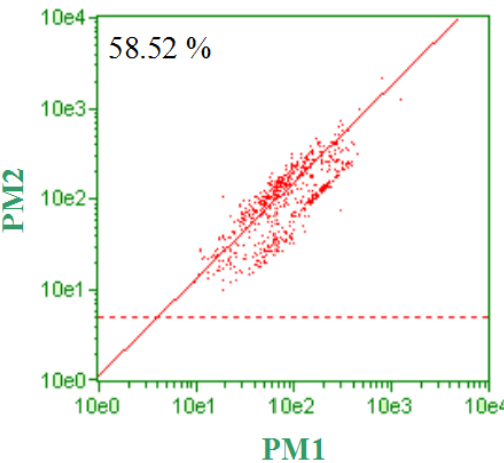

SPV $0.1(\mathrm{mg} / \mathrm{ml})$

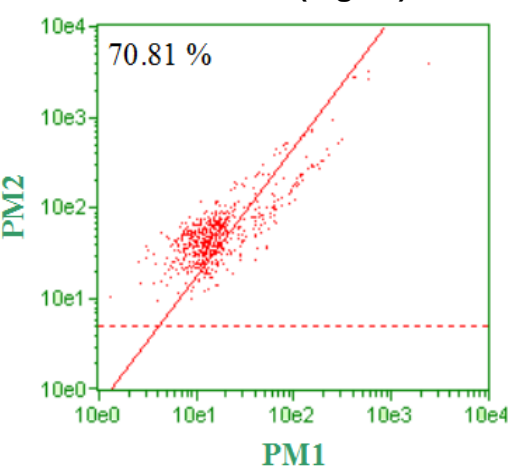

SPV $0.05(\mathrm{mg} / \mathrm{ml})$

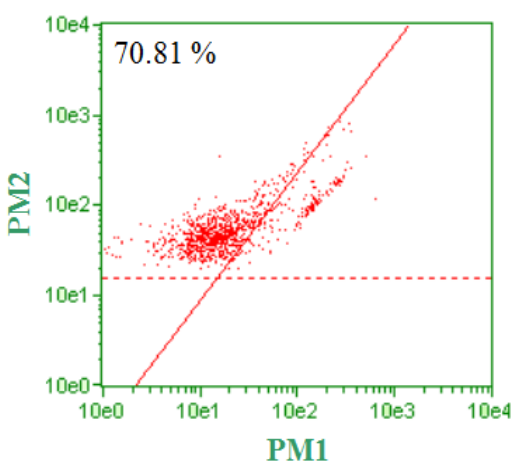

FPV $0.2(\mathrm{mg} / \mathrm{ml})$

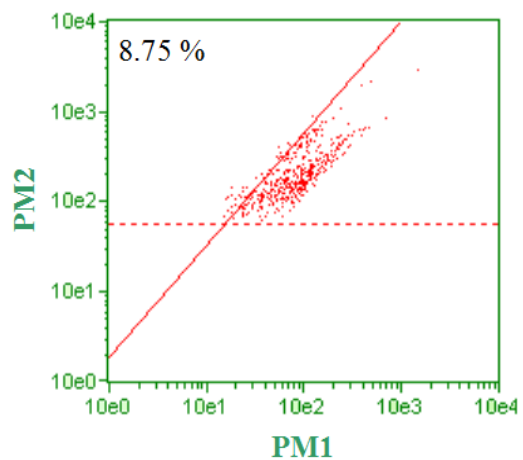

SPV $0.1(\mathrm{mg} / \mathrm{ml})$

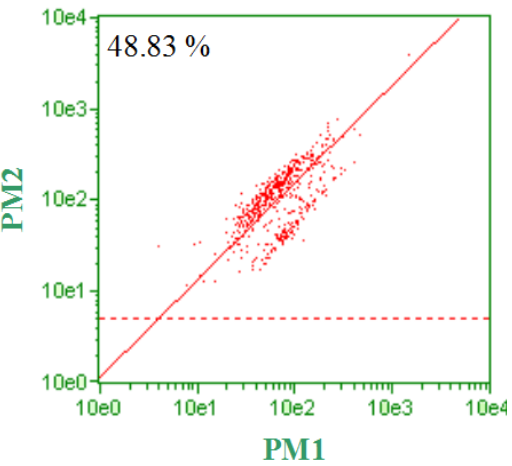

SPV $0.3(\mathrm{mg} / \mathrm{ml})$

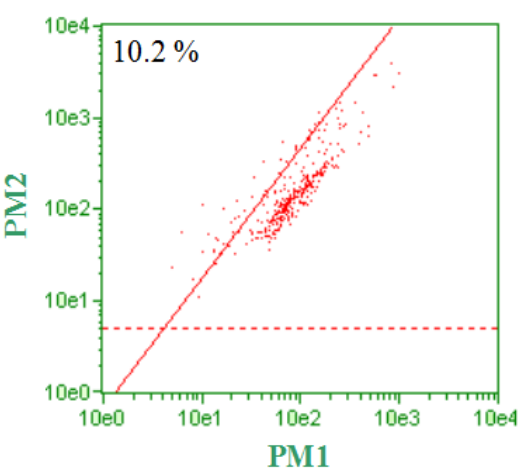

SPV $0.2(\mathrm{mg} / \mathrm{ml})$

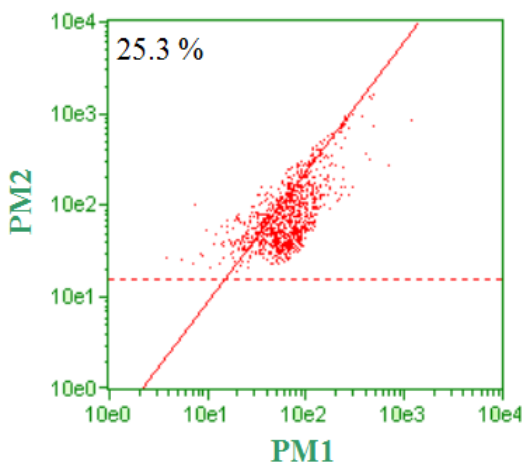

Figure 2. Effects of SPV and FPV on cell apoptosis of different cancer cell lines (L1210 (A), Hela (B), MCF-7 (C), B16 (D)) assayed by flow cytometry. After treated with different concentration SPV and FPV for $48 \mathrm{~h}$, the results of flow cytometry analysis showed the same trend as with MTT assay. 
A

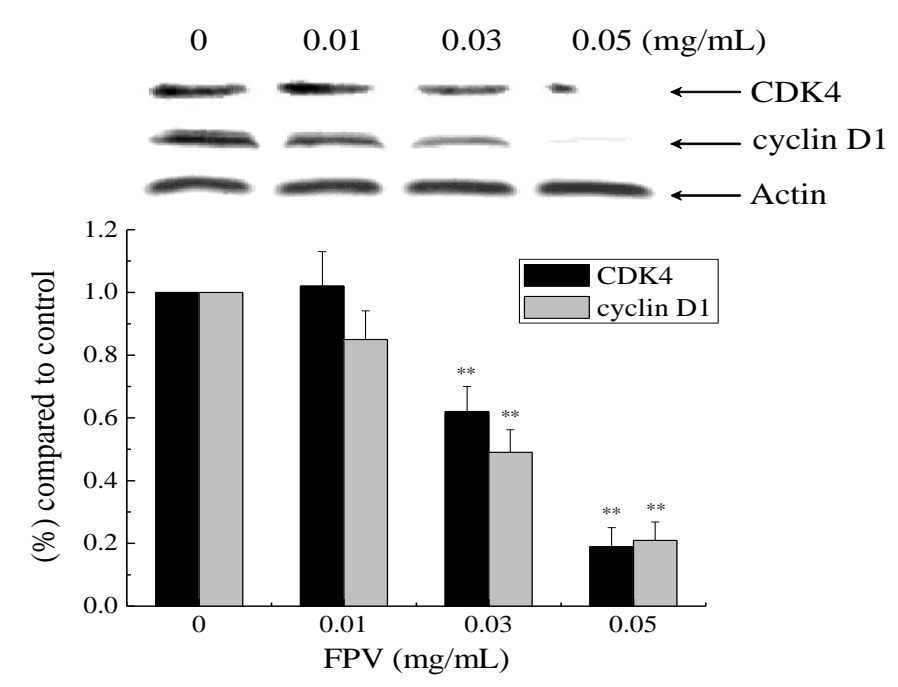

$\mathrm{C}$

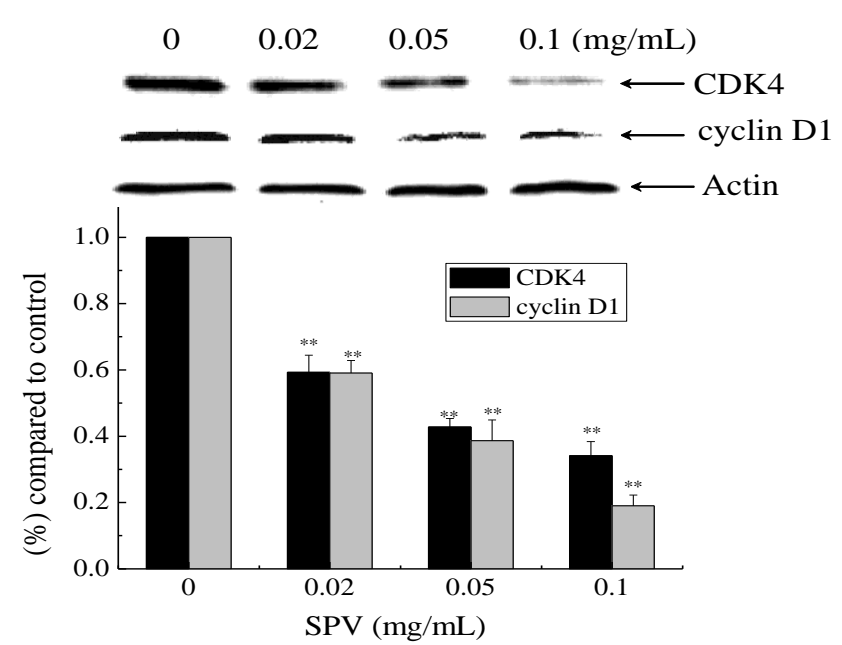

B

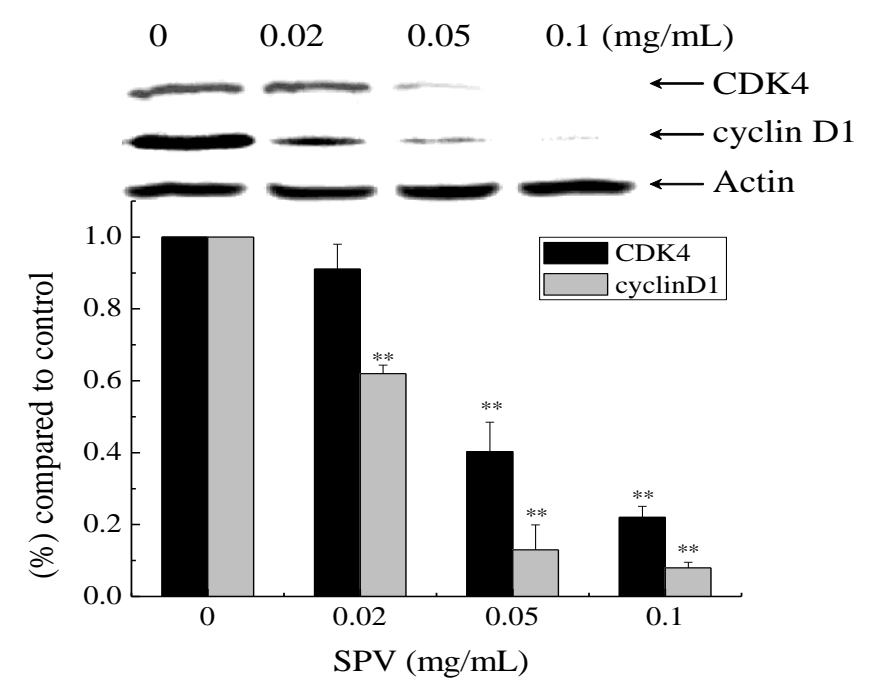

$\mathrm{D}$

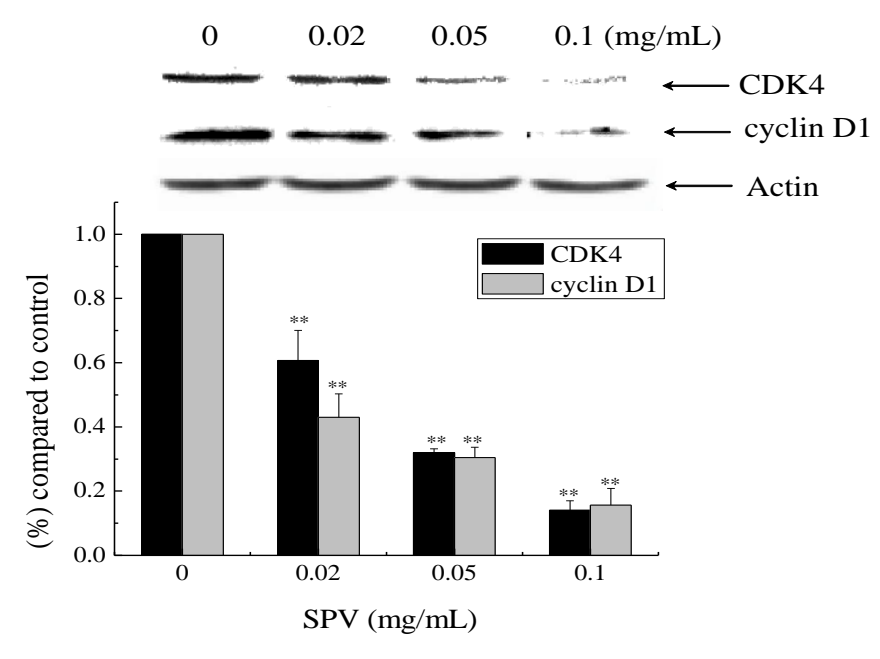

Figure 3. Effects of SPV and FPV on expression of cell cycle-related proteins CDK4 and cyclin D1 in four different cancer cell lines (L1210(A), Hela(B), MCF-7(C), B16(D)). After treated with different concentration SPV and FPV for $48 \mathrm{~h}$, equal cell lysates were separated on $10 \%$ SDS-PAGE. CDK4 and cyclin D1 protein were detected by immunobloting with specific antibodies. Values are the mean \pm SD from three independent experiments. ${ }^{* \star} P<0.01$ versus control. 
Table 1. The effect of SPV and FPV on cell cycle $(n=3$, means \pm SD).

\begin{tabular}{|c|c|c|c|c|c|}
\hline \multirow{2}{*}{ Cell line } & \multirow{2}{*}{\multicolumn{2}{|c|}{ Dose $(\mathrm{mg} / \mathrm{ml})$}} & \multicolumn{3}{|c|}{ Cell cycle (\%) } \\
\hline & & & G0/G1 & $\mathrm{S}$ & G2/M \\
\hline \multirow{3}{*}{ L1210 } & & 0 & 60.6 & 21.6 & 17.7 \\
\hline & FPV & 0.02 & $70.2 \pm 3.23^{* *}$ & $16.4 \pm 1.37^{* *}$ & $13.3 \pm 0.82^{* *}$ \\
\hline & & 0.05 & $76.3 \pm 4.47^{* *}$ & $13.9 \pm 1.01^{* *}$ & $9.8 \pm 1.13^{* *}$ \\
\hline \multirow{3}{*}{ Hela } & & 0 & $56.31 \pm 2.77$ & $21.51 \pm 1.76$ & $22.18 \pm 3.02$ \\
\hline & SPV & 0.05 & $62.92 \pm 3.46^{* *}$ & $15.73 \pm 1.9^{* *}$ & $21.35 \pm 1.24$ \\
\hline & & 0.1 & $69.45 \pm 3.39$ ** & $10.22 \pm 1.37^{* *}$ & $20.33 \pm 2.08$ \\
\hline \multirow{3}{*}{ MCF-7 } & & 0 & $56.5 \pm 2.58$ & $22.42 \pm 3.28$ & $21.08 \pm 2.73$ \\
\hline & SPV & 0.05 & $60.82 \pm 2.17^{* *}$ & $18.86 \pm 2.54^{* *}$ & $20.32 \pm 1.72$ \\
\hline & & 0.1 & $64.16 \pm 3.08^{* *}$ & $15.26 \pm 1.86^{* *}$ & $20.58 \pm 2.33$ \\
\hline \multirow{3}{*}{ B16 } & & 0 & $58.33 \pm 3.47$ & $17.45 \pm 0.98$ & $24.22 \pm 1.82$ \\
\hline & SPV & 0.05 & $61.56 \pm 2.23^{* *}$ & $13.55 \pm 0.66^{* *}$ & $24.89 \pm 2.87$ \\
\hline & & 0.1 & $65.13 \pm 1.46^{* *}$ & $10.73 \pm 1.76^{* *}$ & $24.14 \pm 0.89$ \\
\hline
\end{tabular}

${ }^{*} \mathrm{P}<0.05,{ }^{* *} \mathrm{P}<0.01$ versus control

growth of L1210 cells in a dose-dependent manner $(P<0.01)$. Compared with FPV, SPV showed very significant antiproliferative effects on the other three cell lines, especially on the Hela and B16 cells. Results of flow cytometric analysis also confirmed that FPV and SPV reduced cell viability with the same trend as MTT assay results. This cell type-selective inhibitory effect provided evidence that FPV may have chemopreventive potential on hematopoietic system malignancies (lymphocytic leukemia cancer) and SPV on solid tumors (melanoma, breast cancer, epithelial cervical cancer). Furthermore, it is likely that FPV and SPV have their respective compounds with actives anti-hematopoietic system malignancies and anti-solid tumors, and these results are much more favorable on bioactivity-guided isolations of FPV and SPV.

To further elucidate the mechanism of antiproliferative effects of FPV and SPV on malignancies, other methods for detection were used. A number of investigators observe that the G0/G1 cell cycle arrest and/or the Sphase fraction decrease correlated well with apoptosis (Massague, 2004). Our data confirmed that the cells treated with the P. villosa extracts, both FPV and SPV, exhibited statistically significant block of G0/G1 or G2/M phases, and obviously decrease the S-phase fraction (Table 1). Since cyclins and cyclin-dependent kinases regulate cell cycle progression, the expression of cyclin D1 and CDK4 in cancer cells were determined.

Cellular proliferation follows an orderly progression through the cell cycle, which is regulated by protein complexes that composed of cyclins and cyclindependent kinases. Cyclins are a family of cell cycle control proteins that regulate cell cycle progression by associating with and activating CDKs (Besson et al.,
2008; Musgrove et al., 2011). The deregulated expression of $\mathrm{G} 1$ or $\mathrm{G} 1 / \mathrm{S}$ phase cyclins or their related CDKs may cause loss of cell cycle control and thereby contribute to neoplastic transformation, because the major regulatory events leading to mammalian cell proliferation and differentiation occur in the G0 to $\mathrm{G} 1$ phases or in the $\mathrm{G} 1$ to $S$ phase transition during the cell cycle (Harbour et al., 1999; Hartwell et al., 1994; Hunter et al., 1994). The Kaplan-Meier analysis show that cyclin D1 and CDK4 over expression are significantly associated with disease-free survival and overall survival, and these proteins over expression may play a pivotal role in the biological behavior of malignancies and may provide a strong prognostic implication (Dong et al., 2001). The results showed that SPV and FPV have similar effects in decreasing the protein expression of cyclin D1 and CDK4 protein. These results showed that SPV and FPV might inhibit cyclin D1 and CDK4 protein expression to inhibit tumor growth.

Conclusively, pharmacological data obtained from this study suggested that FPV and SPV possessed cancer chemopreventive potential on different types of cancer cells. The mechanisms involved in cancer chemoprevention by FPV and SPV extracts were cell cycle arrest and induction of apoptosis. A bioactivity-guided approach based on different type of cell lines growth inhibition will be taken to identify the active compounds in FPV and SPV.

\section{ACKNOWLEDGEMENTS}

This work was supported by grants from the Chongqing Science \& Technology committee (2011jjA1396), the 
Innovative Research Team Development Program at the University of Chongqing (No KJTD201020), the Ministry of Education of Chongqing (grant No. KJ100719) and the Natural Science Startup Foundation of Chongqing Technology and Business University (2012-56-02).

\section{REFERENCES}

Besson A, Dowdy SF, Roberts JM (2008). CDK inhibitors: cell cycle regulators and beyond. Dev. Cell. 14: 159-169.

Dong Y, Sui L, Sugimoto K, Tai Y, Tokuda M (2001). Cyclin D1-CDK4 complex, a possible critical factor for cell proliferation and prognosis in laryngeal squamous cell carcinomas. Int. J. Cancer. 95: 209-215.

Harbour JW, Luo RX, Dei Santi A, Postigo AA, Dean DC (1999). Cdk phosphorylation triggers sequential intramolecular interactions that progressively block Rb functions as cells move through $\mathrm{G} 1$. Cell. 98: 859-869.

Hartwell, L.H., Kastan, M.B. (1994). Cell cycle control and cancer. Science. 266: 1821-1828.

Hunter T, Pines J (1994). Cyclins and cancer. II: Cyclin D and CDK inhibitors come of age. Cell. 79: 573-582.

Jeon J, Lee J, Kim C, An Y, Choi C (2010). Aqueous extract of the medicinal plant Patrinia villosa Juss. Induces angiogenesis via activation of focal adhesion kinase. Microvasc. Res. 80: 303-309.

Massague J (2004). G1 cell-cycle control and cancer. Nature. 432: 298306.

Musgrove EA, Caldon C, Barraclough J, Stone A, Sutherland RL (2011). Cyclin D as a therapeutic target in cancer. Nat. Rev. Cancer. 11: 558572.

Peng JY, Fan GR, Chai YF, Wu YT (2006a). Efficient new method for extraction and isolation of three flavonoids from Patrinia villosa Juss. by supercritical fluid extraction and high-speed counter-current chromatography. J. Chromatogr. A. 1102: 44-50.

Peng JY, Fan GR, Hong ZY, Chai YF, Wu YT (2005a). Preparative separation of isovitexin and isoorientin from Patrinia villosa Juss by high-speed counter-current chromatography. J. Chromatogr. A. 1074: 111-115.
Peng JY, Fan GR, Wu YT (2005b). Supercritical fluid extraction of aurentiamide acetate from Patrinia villosa Juss and subsequent isolation by silica gel and high-speed counter-current chromatography. J. Chromatogr. A. 1083: 52-57.

Peng JY, Fan GR, Wu YT (2006b). Preparative isolation of four new and two known flavonoids from the leaf of Patrinia villosa Juss. by counter-current chromatography and evaluation of their anticancer activities in vitro. J. Chromatogr. A. 1115: 103-111.

Peng JY, Fan GR, Wu YT (2006c). Two New Dihydroflavanoids from Patrinia villosa Juss. Chin. Chem. Lett.. 17: 218-220.

Peng JY, Fan GR, Wu YT (2006d). Two New Dihydroflavanoids from Patrinia villosa Juss (II). Chin. Chem. Lett., 17: 485-488.

Peng JY, Yang GJ, Fan GR, Wu YT (2005c). Preparative isolation and separation of a novel and two known flavonoids from Patrinia villosa Juss by high-speed counter-current chromatography. J. Chromatogr. A. 1092: 235-240.

Xu JX, Zhou FQ (2004). Flavonoids Extracting Study on Different Parts of Patrinia Villosa Juss by Four Methods. Guangzhou Food Sci. Technol. 20: 42-43.

Xu JX, Zhou FQ, Jiang FM, Liao YZ (2006). Extraction of total-saponins from Patrinia Villosa Juss based on uniform design method. Chin. Trad. Patent Med. 28: 483-485.

Yang QC, Zhang WZ, Xiao H, Zeng J (2006). Effect of Patrina villosa juss extract on hypoxia tolerance. Chin. J. Clin. Rehabilitat. 10: 177179.

Zhang T, Li Q, Li K, Li Y, Li J, Wang G, Zhou S (2008). Antitumor effects of saponin extract from Patrinia villosa (Thunb.) Juss on mice bearing U14 cervical cancer. Phytother. Res. 22: 640-645. 